\title{
Rancang Bangun Game Edukasi Caru Rsigana Berbasis Android
}

\author{
Pande Made Satrya Dinata, Putu Wira Buana, Ni Made Ika Marini Mandenni \\ Jurusan Teknologi Informasi Fakultas Teknik Universitas Udayana \\ Bukit Jimbaran, Bali, Indonesia, telp. 0361701806 \\ e-mail: pandedinata@gmail.com, wbhuana@gmail.com, ika_made@yahoo.com
}

\begin{abstract}
Abstrak
Caru Rsigana merupakan caru yang dilaksanakan oleh Umat Hindu untuk keseimbangan alam dengan Konsep Tri Hita Karana yaitu Parhyangan, Pawongan, dan Palemahan. Informasi mengenai Caru Rsigana biasanya dituangkan dalam bentuk media buku. Game Caru Rsigana dikembangkan sebagai inovasi baru pengenalan prasarana caru yang diimplementasikan dalam bentuk media pembelajaran berbasis Android. Aplikasi Game Caru Rsigana dibangun menggunakan Corona sebagai sistem debugging dan Bahasa Pemrograman Lua. Aplikasi ini merupakan aplikasi game merangkai atau menyusun sesajen yang dibutuhkan pada Upacara Caru Rsigana yang sesuai dengan letak, arah mata angin, dan warna. Gameplay dari Game Caru Rsigana dibuat dengan konsep drag and drop yaitu menarik sarana caru dan menaruhnya pada tempat sarana caru yang sesuai, serta dengan batas waktu yang telah ditentukan. Data hasil kuesioner Game Caru Rsigana berdasarkan hasil penilaian 20 responden adalah baik, dengan hasil persentase Aspek Visual, Grafis, dan Audio sebesar 86,25\%, serta Aspek Entertainment dan Hiburan sebesar 88,33\%.
\end{abstract}

Kata Kunci: Aplikasi, Game, Sarana Upacara, Android, Caru Rsigana

\section{Abstract}

Caru Rsigana is caru undertaken by Hindus to the balance of nature with the Concept of Tri Hita Karana is Parhyangan, Pawongan, and Palemahan. Information about Caru Rsigana usually manifested in a book medium. Game of Caru Rsigana developed as a new innovation infrastructure caru introduction that is implemented in the form of Android-based learning media. Game of Caru Rsigana application built using Corona as system debugging and programming language Lua. This application is a game application stringing or making offerings is needed on Ceremony of Caru Rsigana corresponding to the location, direction of the wind, and color. The Gameplay of Caru Rsigana's Game created with the concept of drag and drop that is attractive means caru and put in place the appropriate means caru, as well as the time limit specified. Data from the questionnaires Game of Caru Rsigana based on the results of 20 respondents was good, with the percentage Aspects of Visual, Graphics, and Audio amounted to $86.25 \%$, as well as Entertainment and Leisure Aspects of $88.33 \%$.

Keywords: Application, Games, Means of the Ceremony, Android, Caru Rsigana

\section{Pendahuluan}

Game Edukasi Caru Rsigana bisa menjadi wadah atau media interaktif sebagai pelestarian budaya khususnya Budaya Bali dan kearifan lokal. Game saat ini masih sedikit mengangkat tentang budaya dan adat-istiadat khususnya di Bali. Hal ini menunjukkan bahwa diperlukannya sebuah game mengenai budaya yang mudah digunakan dan dipahami masyarakat pada umumnya dan juga dengan tampilan serta pengemasan yang menarik. Game edukasi dapat membantu dalam mempelajari kebudayaan daerah khususnya mengenai membuat Caru Rsigana [1].

Caru Rsigana merupakan caru yang dilaksanakan untuk keseimbangan alam dengan konsep Tri Hita Karana yaitu Parhyangan, Pawongan, dan Palemahan. Caru dipersembahkan kepada alam untuk keharmonisan dalam hubungan alam dan manusia. Caru Rsigana adalah sebagai lambang atau sesajen yang dihaturkan untuk memohon penyucian pada suatu tempat 
agar kembali harmonis [1].

Game edukasi berbudaya yang telah dikembangkan diantaranya oleh Ida Bagus Danni Krisnawan dengan "Rancang Bangun Game Edukasi Lawar Bali" dan Ida Ayu Wahyu Kumara Putri dengan "Game Edukasi Banten Pejati pada Smartphone Berbasis Android".

Game Lawar Bali adalah game langkah-langkah cara membuat lawar serta mengetahui bahan-bahan yang dibutuhkan pada pembuatan lawar di Bali. User dapat menyusun bahan yang digunakan dalam membuat lawar. Game dikembangkan bertujuan untuk menarik minat anak-anak mempelajari masakan tradisional Khas Bali [2].

Tujuan pembuatan Game Edukasi Banten Pejati yaitu memperkenalkan Banten Pejati pada Umat Hindu, khususnya anak-anak. Game Banten Pejati manampilkan berbagai macam banten sebagai penyusun Banten Pejati yang digunakan pada setiap pelaksanaan upacara keagamaan oleh Umat Hindu [3].

Game Caru Rsigana merupakan game yang mengangkat tentang budaya di Bali dengan mengambil tema game edukasi mengenai tata cara merangkai persembahan sesajen (caru) menurut adat-istiadat Bali. Game Caru Rsigana dirancang menggunakan fitur drag and drop yang berfungsi untuk merangkai sesajen dalam proses permainan dibangun sehingga user lebih mudah untuk mengerti bagaimana cara memainkan Game Caru Rsigana. Game Caru Rsigana dikembangkan untuk diimplementasikan pada smartphone berbasis Android. Game Caru Rsigana bertujuan untuk memberikan informasi mengenai cara merangkai sarana sesajen serta pemahaman tentang Caru Rsigana sekaligus melestarikan adat-istiadat Budaya Bali. Game Edukasi Caru Rsigana diharapkan dapat menjadi wadah atau media interaktif pendukung pelestarian budaya khususnya Budaya Bali dan kearifan lokal.

\section{Metodologi Penelitian}

Game Edukasi Caru Rsigana merupakan suatu game yang mengajarkan untuk membuat Caru Rsigana sesuai dengan petunjuk atau tutorial yang ada pada permainan. Alur permainan dari game edukasi ini, untuk lebih jelasnya dapat dilihat pada Gambar 1.

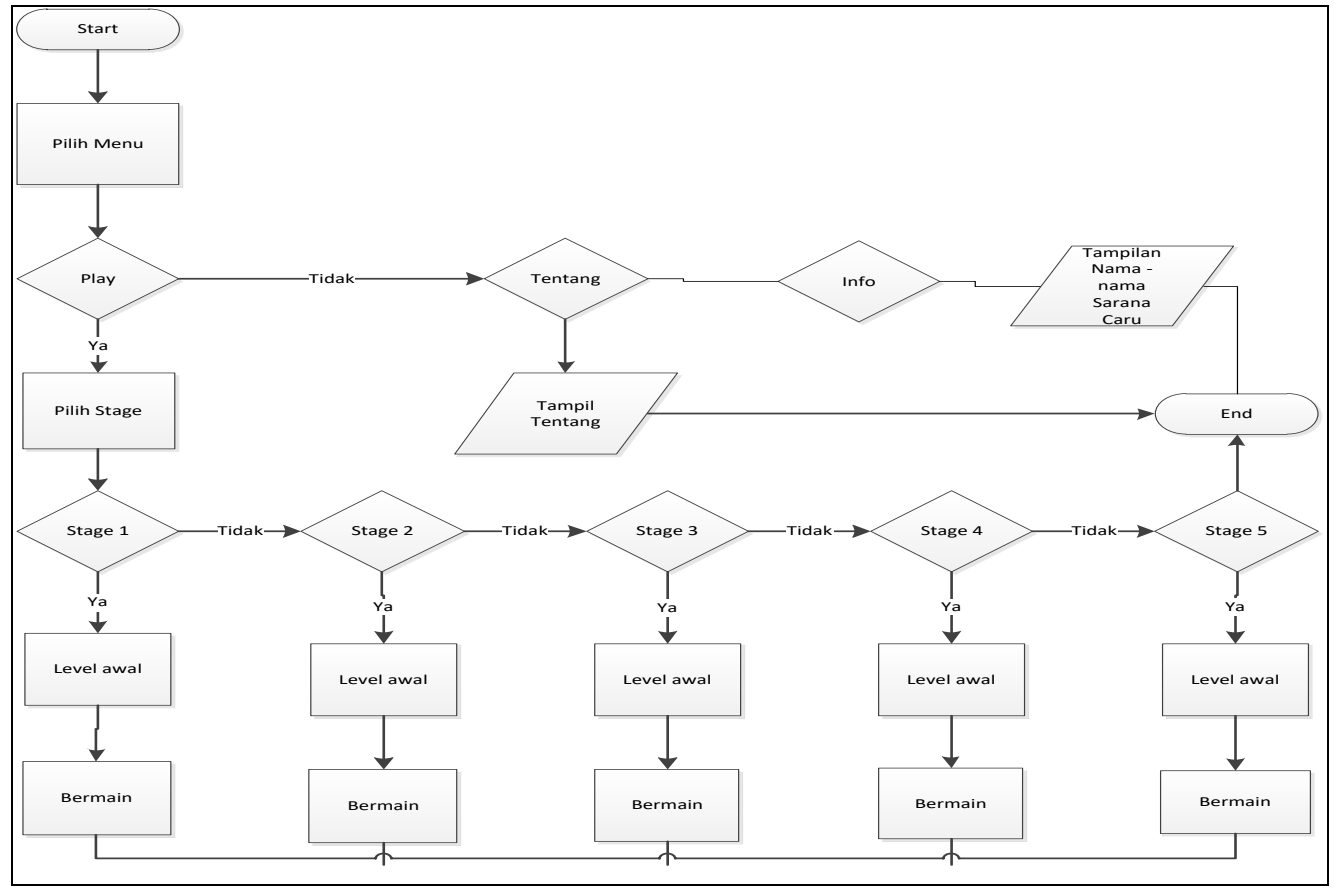

Gambar 1. Flowchart Alur Program

Flowchart Alur Program ditunjukan pada Gambar 1. Alur program dimulai dari Home Screen yang terdapat pilihan Play dan Tentang. Button Play digunakan untuk masuk ke dalam permainan. Button Play dimulai dengan pemilihan stage dan terdapat 5 stage pada pemilihan stage. Stage memiliki beberapa level yang akan dilewati oleh user. Permainan dimulai dengan menyusun dan merangkai bahan-bahan yang digunakan pada Caru Rsigana, merangkai bahan 
sesajen sesuai warna dan letak dari sesajaen tersebut dan menetukan aksara serta dewa yang melambangkan dari warna serta letak dari Caru Rsigana tersebut.

\section{Kajian Pustaka}

\subsection{Caru Rsigana}

Caru Rsigana adalah caru yang merupakan keputusan Sang Hyang Resi Ghana diperoleh dari Sang Aji Guru untuk "Pemarisudhaning Karang Angker" atau penyucian terhadap semua jenis pekarangan angker akibat dari adanya suatu musibah yang menimbulkan terjadinya situasi memanas yang dirasakan oleh yang punya atau penghuninya secara lahir dan batin. Caru Rsigana bentuknya adalah berua upakara atau banten yang dipakai sebagai sarana dalam Upacara Bhuta Yadnya untuk memohon penyucian terhadap pekarangan yang angker itu agar kembali harmonis dan suci dirasakan oleh penghuninya [1].

Sarana yang digunakan dalam menyusun Banten Caru Rsigana terdapat beberapa item diantaranya:

1. Sanggah Cucuk

Sanggah Cucuk dibuat dari setangkai bambu kecil yang ujungnya dibelah menjadi empat bagian. Bagian atasnya dipasangkan kelakat sehingga membentuk bidang segi empat dan bisa juga diberi kelakat yang dibentuk menyerupai atap rumah. Sanggah Cucuk diisi secarik kain yang sesuai dengan letak dan warnanya

2. Layang-layang

Layang-layang merupakan kulit ayam yang masih lengkap dengan bulunya termasuk kepala, sayap dan kakinya masih melekat dan berhubungan satu dengan yang lainnya. Layang-layang pada Caru Rsigana menggunakan lima jenis ayam yaitu Ayam Hitam, Ayam Putih, Ayam Brumbun, Ayam Putih Syungan atau Ayam Buik Kuning yang melambangkan warna kuning, dan Ayam Biying (Merah).

3. Taledan Caru

Taledan Caru adalah taledan yang terbuat dari daun kelapa yang tersusun atas beberapa lembar daun kelapa yang biasa disebut dengan slepan dan ada juga yang menggunakan janur sehingga membentuk bidang segi empat dan diberi hiasan menyerupai kelopak bunga dipinggir bidang segi empat tersebut. Taledan Caru adalah alas untuk tempat menata tempat nasi serta bahan-bahan yang dibutuhkan. Tempat nasi pada taledan caru ini terdapat tiga jenis tempat nasi yaitu Tekor, Bogu, dan Telapakan. Jumlah tempat nasi yang digunakan pada Taeldan Caru tergantung pada jumlah urip hewan yang digunakan pada caru. Nasi yang digunakan sesuai dengan warna dari hewan.

\subsection{Game}

Game merupakan kata dari bahasa asing yaitu Bahasa Inggris. Bahasa Indonesia mengatakan makna "Game" adalah sebuah permainan. Game adalah unsur daripada bermain dan bermain juga merupakan unsur dari permainan sehingga keduanya saling berhubungan. Pengertian game mengacu pada kelincahan intelektual (Intellectual Playability Game) dan dapat dimaknai untuk tempat media keputusan dan tindakan pemainnya. Hans Daeng mengatakan bahwa [4] game adalah unsur seutuhnya dari kehidupan anak dan permainan adalah rangkaian terjadinya penyusunan kepribadian anak pada unsur integral. Andang Ismail mengatakan bahwa game mempunyai dua makna [5] yaitu yang pertama game merupakan sebuah kegiatan bermain untuk mendapatkan kesenangan tanpa mengharapkan menang dan kalah. Makna game yang kedua yaitu game dimaknai sebagai keaktifan bermain yang dilaksanakan untuk mencapai kesenangan dan kepuasan, tetapi diiringi memperoleh menang kalah. Kimpraswil [6] menyebutkan bahwa arti game yaitu kegiatan olah jiwa dan raga yang penting bagi pertumbuhan dan pembentukan motivasi, kinerja, dan prestasi pada pelaksanaan tugas dan kepentingan kelompok menjadi lebih baik.

\subsection{Android}

Android merupakan perangkat lunak untuk perangkat berbasis mobile yang meliputi sistem operasi, middleware dan aplikasi kunci. Sistem Operasi Android SDK menyiapkan tools serta Application Programming Interface yang biasa disebut dengan API dan dibutuhkan untuk mengawali merancang aplikasi pada Platform Android memakai Bahasa Pemrograman Java. 
Siste Operasi Android yaitu sistem operasi dengan berbasis Linux. Android memberikan platform terbuka kepada pengembang untuk dapat membuat suatu aplikasi mereka sendiri. Google Inc. pada awalnya membeli Android Inc., yang merupakan pendatang baru yang membuat perangkat lunak untuk ponsel. Lalu dalam proses mengembangkan Android, dibentuklah Open Handset Alliance [7].

\subsection{Corona SDK}

Corona merupakan sebuah tools yang mendukung pengembangan aplikasi pada Operation Sistem iOS \& Android. Corona bisa menciptakan suatu perangkat lunak serta bisa dijalankan pada sistem operasi yang berbeda. Corona tidak memiliki editor sendiri melainkan corona memakai perangkat editing script dasar sebagai media merancang script program serta editor grafis untuk membuat gambar. Corona hanya bertugas untuk menyusun dan running program. Untuk dapat menjalankan Corona, user memerlukan API dari Corona serta editing script yang support pada Corona. Corona sendiri adalah perangkat lunak yang sesuai dalam perancangan sistem game permaian. Perangkat Lunak Corona memiliki ekstensi data berbasis Lua [8].

\subsection{LUA}

Lua dirancang, diimplementasikan, dan dipelihara oleh tim di PUC-Rio. Lua lahir dan dibesarkan di Tecgraf, Komputer Grafis Technology Group dari PUC-Rio, dan sekarang bertempat di Lablua [8]. Bahasa Lua merupakan bahasa pemrograman yang tidak lambat serta size-nya yang sederhana dan bisa digunakan lebih sederhana pada sistem. Bahasa Lua mempunyai API sederhana dan terdokumentasi, dan dapat terhubung dengan erat pada kode yang dirancang menggunakan bahasa yang berbeda. Bahasa Lua mudah dalam mengembangkan Lua dengan library yang dirancang pada bahasa yang berbeda. Bahasa Pemrograman Lua sudah dipakai untuk memperdalam code yang dirancang, dan tidak hanya di C dan $\mathrm{C}++_{+}$tetapi juga di Java, C\#, Smalltalk, Fortran, Ada, Erlang, dan bahkan dalam bahasa script lainnya, seperti Perl dan Ruby. Lua menyatukan code program yang simple serta data description, yang dilandasi oleh array asosiatif dan semantik extensible. Lua dinamis diketik, dijalankan dengan menerjemahkan bytecode pada mesin virtual, dan mempunyai pengaturan penyimpanan otomatis dengan penampungan sampah yang ditambah, sehingga ideal untuk konfigurasi, scripting, dan prototyping cepat [3].

\subsection{Kuesioner}

Kuesioner merupakan penampungan informasi sebuah penelitian memakai susunan pertanyaan yang dijawab oleh para responden. Bentuk dari kuesioner dibagi menjadi tiga bagian yaitu kuesioner tertutup, kuesioner terbuka dan kuesioner tertutup-terbuka. Kuesioner tertutup, yaitu kuesioner dengan menyiapkan pilihan jawaban atas pertanyaan yang disiapkan, agar responden tidak memiliki kebebasan dalam menjawab pertanyaan. Kuesioner terbuka, adalah kuesioner yang tidak menyiapkan jawaban atas pertanyaan yang diberikan, maka dari itu responden dapat dengan bebas untuk menjawab jawabannya. Kuesioner pada bagian kuesioner tertutup-terbuka, adalah gabungan dari bagian kuesioner tertutup dan terbuka. Kuesioner juga masih dibagi menjadi kuesioner langsung serta kuesioner tidak langsung. Kuesioner langsung, yaitu kuesioner yang secara langsung diserahkan kepada pihak responden untuk menjawab dari pertanyaan atau pernyataan yang tanpa disertai perantara. Kuesioner tidak langsung, merupakan kuesioner yang secara tidak langsung diserahkan kepada pihak responden untuk menjawab pertanyaan atau pernyataan dengan menggunakan perantara [9].

\section{Hasil dan Pembahasan}

Game Edukasi Caru Rsigana dapat di-install di Device Android dengan sistem operasi minimal yaitu Android Versi 2.2 (Froyo: Frozen Yoghurt). Hasil print screen dari Game Edukasi Caru Rsigana dijelaskan pada hasil dan pembahasan. Survey dilaksanakan agar dapat meneliti respon pemain dengan memberikan kuesioner, persentase hasil survey disajikan dalam bentuk diagram venn.

\subsection{Tampilan Game Caru Rsigana}

Sub Bab Tampilan Game Caru Rsigana membahas mengenai tampilan Game Caru 
Rsigana. Tampilan yang terdapat pada Game Caru Rsigana diantaranya Tampilan Menu Utama, Scene Stage, Scene Credit, Scene Toturial, dan Scene Permainan.

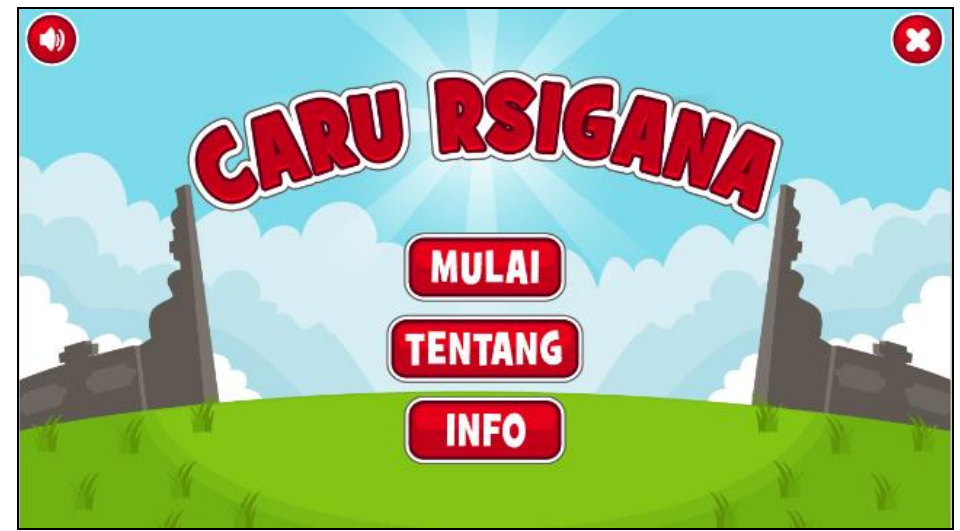

Gambar 2. Scene Menu Utama

Tampilan Scene Menu Utama ditunjukkan pada Gambar 2. Tampilan Scene Menu Utama memiliki beberapa button yaitu Button Mulai, Button Tentang, Button Info, Button Sound, dan Button Exit. Pengguna dapat memulai permainan dengan memilih Button Mulai.

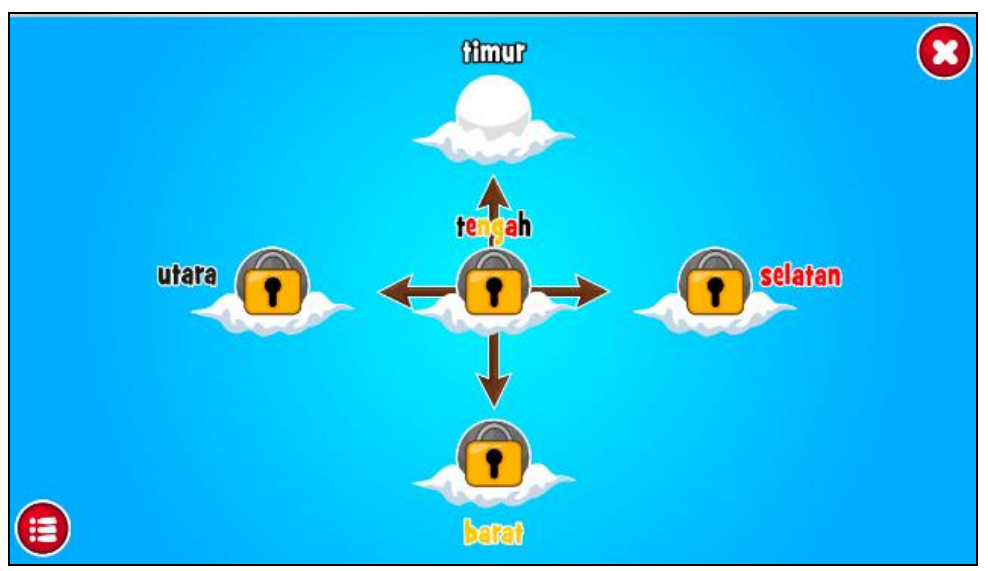

Gambar 3. Scene Stage

Gambar 3 merupakan Tampilan Scene Stage dari Game Caru Rsigana. Scene Stage memiliki lima stage yang sesuai dengan letak dan arah mata angin. Setiap stage memiliki beberapa level yang kesulitannya sesuai dengan warna dan jumlah urip.

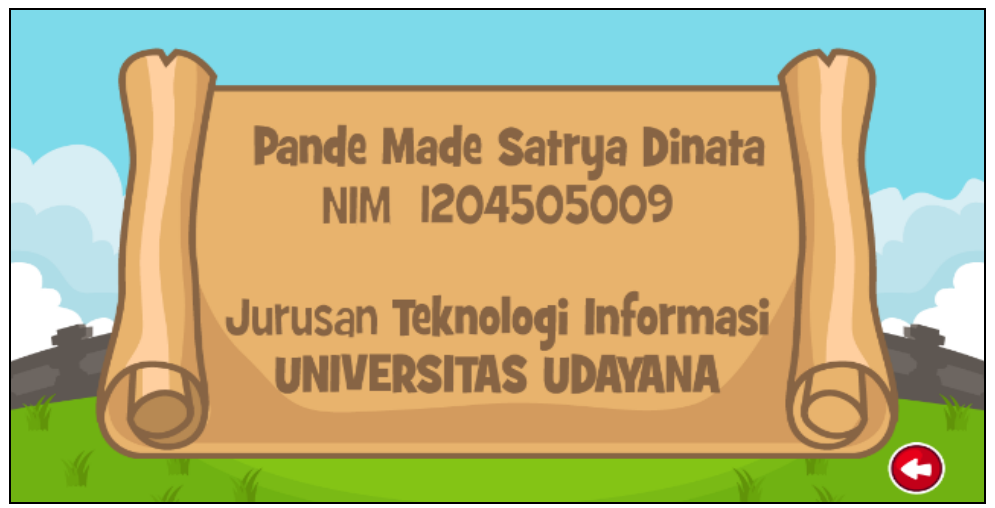

Gambar 4. Scene Credit

Tampilan Scene Credit yang berisikan informasi tentang profil singkat dari developer dapat dilihat pada Gambar 4. Tampilan Scene Credit terdapat Button Back untuk kembali ke 
Menu Utama.

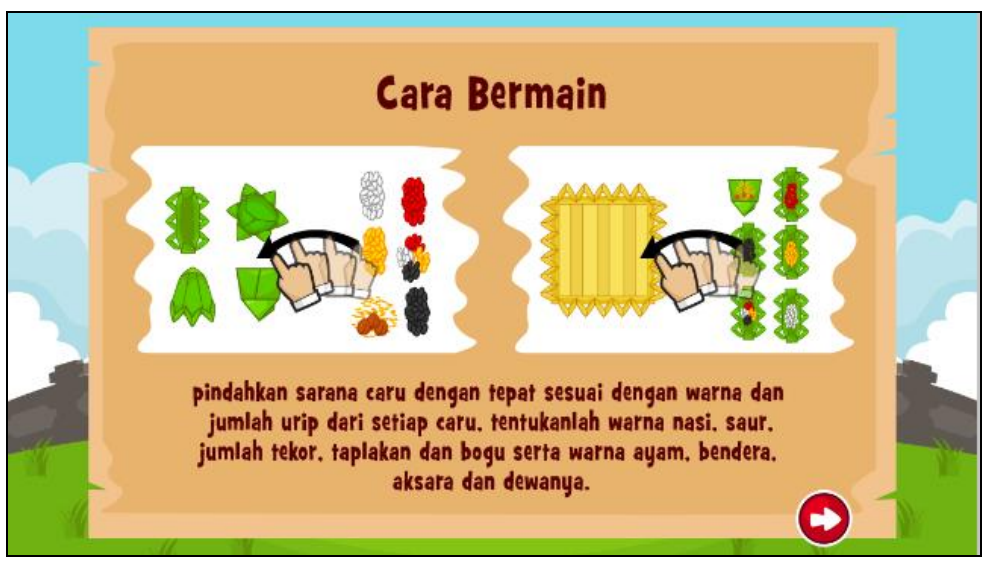

Gambar 5. Scene Tutorial

Gambar 5 merupakan Scene Tutorial dalam bentuk gambar yang berisi penjelasan bagaimana cara memainkan Game Caru Rsigana. Tampilan Scene Toturial memiliki Button Next yang digunakan untuk memulai permainan.

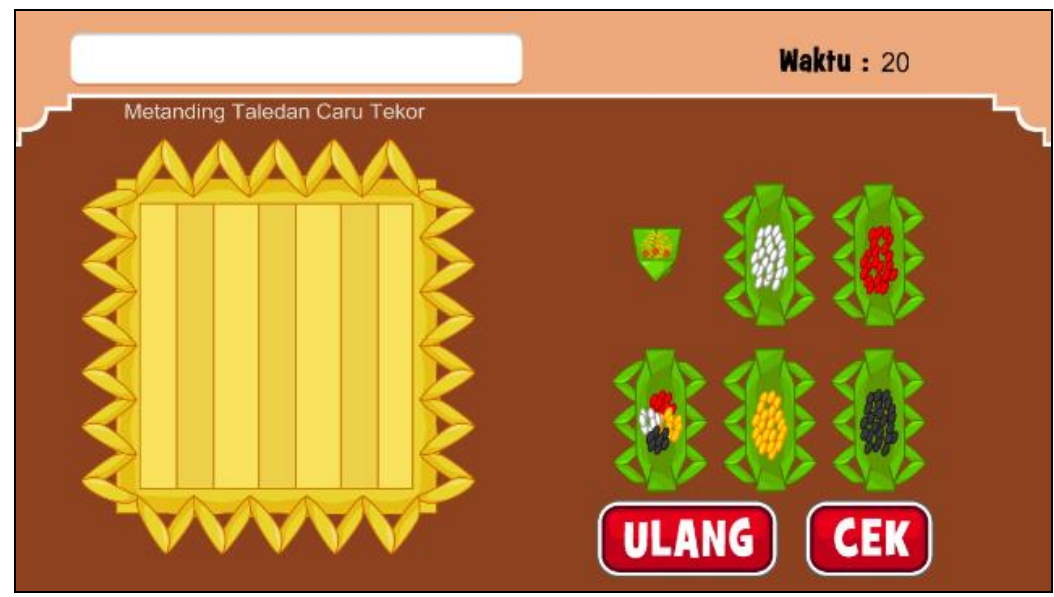

Gambar 6. Scene Permainan

Scene Permainan pada Gambar 6 merupakan scene pada saat memainkan permainan merangkai Taledan Caru. Tampilan scene ini muncul pada saat memilih stage yang ingin dimainkan.

\subsection{Hasil Analisa}

Analisa sistem dilakukan dengan metode survey, penetapan variabel, pengumpulan data, penyajian data dan analisa untuk mengelola data. Kuesioner digunakan untuk mendapatkan persentase pada masing-masing kriteria yang memiliki nilai tertinggi dan terendah dari masingmasing aspek (sangat baik, baik, cukup baik, dan kurang).

\subsubsection{Aspek Grafis, Visual, dan Audio}

Aspek Grafis, Visual,dan Audio ditujukan untuk mendapatkan penilaian dari sisi disain user interface dari game edukasi. Aspek Grafis, Visual, dan Audio meliputi:

1. Visual (layout design dan warna)

2. Audio (sound effect dan background)

3. Media bergerak (animasi)

4. Bentuk banten jelas dan mudah dikenali 
Tabel 1. Penilaian aspek grafis visual

\begin{tabular}{|c|c|c|c|c|c|}
\hline \multicolumn{6}{|c|}{ Aspek Grafis, Visual, dan Audio } \\
\hline No & Kriteria & Kurang Baik & $\begin{array}{c}\text { Cukup } \\
\text { Baik }\end{array}$ & Baik & $\begin{array}{c}\text { Sangat } \\
\text { Baik }\end{array}$ \\
\hline 1 & $\begin{array}{l}\text { Visual (layout design, dan } \\
\text { warna) }\end{array}$ & 0 & 1 & 2 & 17 \\
\hline 2 & $\begin{array}{l}\text { Audio (Sound Effect dan } \\
\text { backgorund) }\end{array}$ & 0 & 0 & 0 & 20 \\
\hline 3 & Media Bergerak (Animasi) & 1 & 0 & 3 & 16 \\
\hline \multirow[t]{2}{*}{4} & $\begin{array}{l}\text { Bantuk banten jelas dan } \\
\text { mudah dikenali }\end{array}$ & 0 & 1 & 3 & 16 \\
\hline & Total Skor & $\mathbf{1}$ & 2 & 8 & 69 \\
\hline
\end{tabular}

Keterangan:

1 : Kurang

2 : Cukup

3 : Baik

4 : Sangat Baik

Berdasarkan Tabel 1, maka dapat ditarik kesimpulan sebagai berikut:

1. Jumlah responden sebanyak 20 orang.

2. Jumlah kriteria pada aspek tersebut 4.

3. Total skor responden yang memilih kurang baik sebanyak 1 dan hasil persentasenya sebesar $(0.25 / 20)^{*} 100 \%=1.25 \%$

4. Total skor responden yang memilih cukup baik sebanyak 2 dan hasil persentasenya sebesar $(0.025 / 20)^{*} 100 \%=2.5 \%$

5. Total skor responden yang memilih baik sebanyak 8 dan hasil persentasenya sebesar $(0.1 / 20)^{*} 100 \%=10 \%$

6. Total skor responden yang memilih sangat baik sebanyak 69 dan hasil persentasenya sebesar $(0.8625 / 20)^{*} 100 \%=86.25 \%$

7. Sebagian besar responden memberikan respon persentase kurang sebanyak $1,25 \%$, cukup baik sebanyak $2,25 \%$, baik sebanyak $10 \%$ dan sangat baik sebanyak $86,25 \%$ pada Aspek Grafis, Visual, dan Audio pada Game Caru Rsigana. Hasil persentase yang sudah diperoleh, pilihan persentase tertinggi terdapat pada pilihan sangat baik, sehingga dapat disimpulkan game media pembelajaran ini sebagai sarana hiburan dan edukasi yang menarik dan dapat dimengerti oleh anak-anak.

Berdasarkan persentase diatas, maka gambaran dalam bentuk diagram dapat dilihat pada Gambar 10. 


\section{Aspek Grafis, Visual, dan Audio}

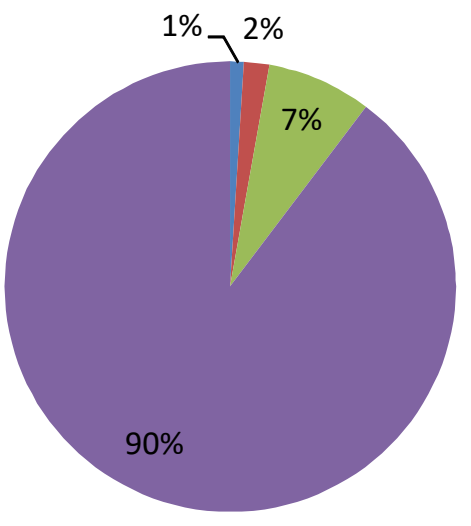

- Kurang Baik

- Cukup Baik

Baik

- Sangat Baik

Gambar 10. Diagram aspek grafis visual

\subsubsection{Aspek Entertainment dan Pembelajaran}

Aspek Entertainment dan Pembelajaran ditujukan untuk mendapatkan penilaian dari sisi pembuatan game dan mengetahui apakah setelah memainkan game edukasi ini user mampu menerapkannya pada kehidupan sehari-hari. Aspek Entertainment dan Pembelajaran meliputi:

1. Kejelasan tujuan pembelajaran

2. Pemberian motivasi belajar

3. Kemudahan untuk dipahami

4. Tingkat kesulitan permainan

5. Media hiburan yang menyenangkan

6. Mendapat pemahaman cara membuat Banten Caru

Tabel 2. Penilaian Aspek Entertainment dan Pembelajaran

\begin{tabular}{|l|l|c|c|c|c|}
\hline \multicolumn{6}{|l|}{ Aspek Entertaiment dan Pembelajaran } \\
\hline No & Kriteria & $\begin{array}{l}\text { Kurang } \\
\text { Baik }\end{array}$ & $\begin{array}{l}\text { Cukup } \\
\text { Baik }\end{array}$ & Baik & $\begin{array}{l}\text { Sangat } \\
\text { Baik }\end{array}$ \\
\hline 1 & Kejelasan tujuan pembelajaran & 0 & 0 & 2 & 18 \\
\hline 2 & Pemberian motivasi belajar & 0 & 0 & 1 & 19 \\
\hline 3 & Kemudahan untuk dipahami & 1 & 0 & 3 & 17 \\
\hline 4 & Tingkat kesulitan permainan & 0 & 1 & 5 & 14 \\
\hline 5 & Media hiburan yang menyenangkan & 0 & 0 & 1 & 19 \\
\hline 6 & $\begin{array}{l}\text { Mendapat pemahaman tentang } \\
\text { Banten Caru }\end{array}$ & 0 & 1 & 0 & 19 \\
\hline & Total Skor & $\mathbf{1}$ & $\mathbf{2}$ & $\mathbf{1 2}$ & $\mathbf{1 0 6}$ \\
\hline
\end{tabular}

Keterangan:

1 : Kurang

2 : Cukup

3 : Baik 


\section{4 : Sangat Baik}

Berdasarkan Tabel 2, maka dapat ditarik kesimpulan sebagai berikut:

1. Jumlah responden sebanyak 20 orang.

2. Jumlah kriteria pada aspek tersebut 6 .

3. Total skor responden yang memilih kurang baik sebanyak 1 dan hasil persentasenya sebesar $(0.167 / 20)^{*} 100 \%=0.83 \%$

4. Total skor responden yang memilih cukup baik sebanyak 2 dan hasil persentasenya sebesar $(0.33 / 20)^{*} 100 \%=1.67 \%$

5. Total skor responden yang memilih baik sebanyak 12 dan hasil persentasenya sebesar $(2 / 20)^{*} 100 \% 10 \%=10 \%$

6. Total skor responden yang memilih sangat baik sebanyak 106 dan hasil persentasenya sebesar $(17.67 / 20)^{*} 100 \%=88.33 \%$

7. Sebagian besar responden memberikan respon persentase kurang baik sebanyak $0,83 \%$, cukup baik sebanyak $1,67 \%$, baik sebanyak $10 \%$ dan sangat baik sebanyak $88.33 \%$ pada Aspek Entertaiment dan Pembelajaran pada Game Caru Rsigana. Berdasarkan hasil persentase yang sudah diperoleh, pilihan persentase tertinggi terdapat pada pilihan sangat baik, sehingga dapat disimpulkan game media pembelajaran ini dapat menjadi sarana hiburan dan edukasi yang menarik, serta dapat dimengerti oleh anak-anak.

Berdasarkan persentase diatas, maka gambaran dalam bentuk diagram dapat dilihat pada Gambar 11.

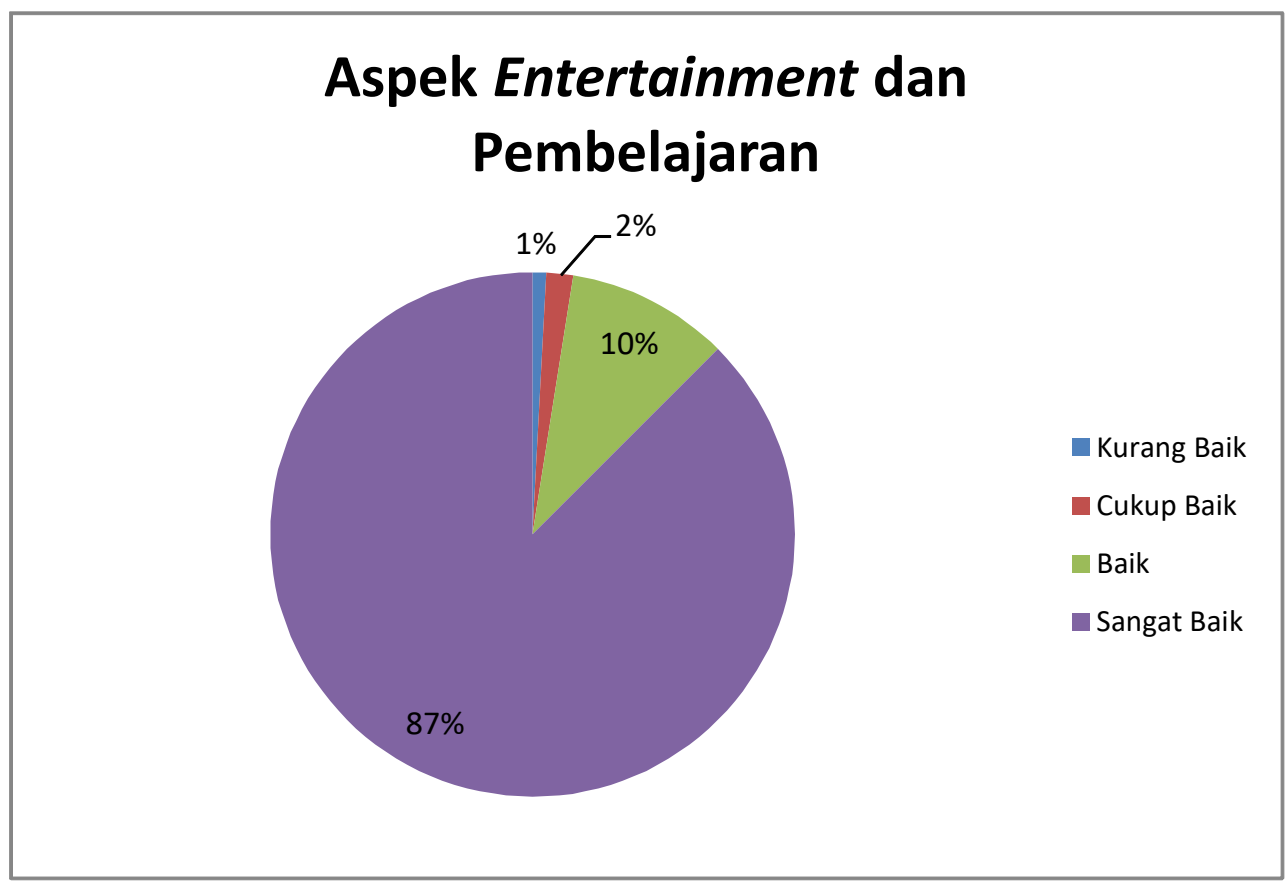

Gambar 11. Diagram Aspek Entertainment dan Pembelajaran

\section{Simpulan}

Game Edukasi Caru Rsigana dapat menjadi referensi baru kepada masyarakat dalam hal sarana bermain dan belajar bagaimana cara membuat sarana untuk Upacara Caru Rsigana dengan baik dan benar secara lebih menarik dan mendidik. Berdasarkan kuesioner, $86.25 \%$ dari 20 responden menyatakan Game Edukasi Caru Rsigana memiliki visual, grafik, dan audio yang sangat baik. Game Caru Rsigana baik sebagai media hiburan dan pembelajaran, berdasarkan kuesioner, 88.33\% dari 20 responden menyatakan Game Edukasi Caru Rsigana merupakan media belajar dan media hiburan yang sangat baik. Secara keseluruhan Game Edukasi Caru Rsigana memiliki tampilan yang baik dan cukup mudah dimengerti oleh pengguna serta baik digunakan sebagai media hiburan dan media pembelajaran. 


\section{Daftar Pustaka}

[1] Arwati NMS. Caru Resi Ghana. Denpasar: Upada Sastra Denpasar. 2005

[2] Krisnawan IBD. Rancang Bangun Game Edukasi Lawar Bali pada Platform Android, Merpati. 2014; 2(1): 58-66

[3] Kumara IAP, Sudana AAKO, Ika NMMM. Game Edukasi Banten Pejati pada Smartphone berbasis Android, Merpati. 2014; 2(2): 146-156

[4] Yuliastin NK. Program Kreativitas Mahasiswa Rancang Bangun Game Edukatif Busana Tari Bali Berbasis Android. Program Kreativitas Mahasiswa Karya Cipta. Teknologi Informasi Fakultas Teknik Universitas Udayana. 2013; 1-23

[5] Ismail A. Education Games Panduan Praktis Permainan yang Menjadikan Anak Anda Cerdas, Kreatif dan Shaleh. Yogyakarta: Pro U Media. 2009; 7-27

[6] Muhammad A. Menghidupkan Otak Kanan Anak Anda. Yogyakarta: Power Books. 2009; 26

[7] Huda AA. LIVECODING! 9 Aplikasi Android Buatan Sendiri. Yogyakarta: ANDI Yogyakarta. 2013

[8] Burton B. Learning Mobile Application \& Game Development with Corona SDK. Texas, United States of America: Abilene. 2013

[9] Arikunto S. Prosedur Penelitian Suatu Pendekatan Praktik. Jakarta: Rineka Cipta. 2006 